\title{
Multifocal gastric neoplasia after recurrent laser therapy for the watermelon stomach
}

Charles N Bernstein MD, Norman Pettigrew MD, Kenneth K Wang MD, Howard Greenberg MD, Jeremy Lipschitz MD

CN Bernstein, N Pettigrew, KK Wang, H Greenberg, J Lipschitz. Multifocal gastric neoplasia after recurrent laser therapy for the watermelon stomach. Can J Gastroenterol 1997;11(5): 403-406. Repeated laser therapy has become an accepted therapeutic approach in the treatment of watermelon stomach, and to date no important negative sequelae have been reported. The case of a patient who underwent repeated sessions of neodymium: yttrium aluminum garnet $(\mathrm{Nd}: \mathrm{YAG}$ ) laser therapy over a five-year period for the treatment of the watermelon stomach is presented. Postlaser therapy the patient developed deep ulcerations that would heal; however, he ultimately developed a nodular antrum. Random biopsies of antral nodules revealed carcinoma-in-situ. A Billroth I gastrectomy revealed two foci of carcinoma-in-situ/high grade dysplasia and multiple foci of lower grades of dysplasia. This case suggests a possible association between use of laser therapy and development of gastric neoplasia.

Key Words: Carcinoma-in-situ, Gastric antral vascular ectasia (GAVE), Nd:YAG laser, Watermelon stomach

\author{
Néoplasie gastrique multifocale après \\ traitement au laser répété de l'estomac pastèque
}

RÉSUMÉ : Le traitement répété au laser est devenu une approche thérapeutique acceptée pour le traitement de l'estomac pastèque et à ce jour, aucune séquelle négative importante n'avait été signalée. Le cas d'un patient ayant subi des séances répétées de traitement au laser Nd:YAG au cours d'une période de cinq ans pour le traitement d'un estomac pastèque est présenté ici. Après ce type de traitement, le patient a développé des ulcères profonds qui ont cicatrisé. Toutefois, il a éventuellement développé des nodules au niveau de l'antre. Des biopsies aléatoires des nodules antraux ont révélé la présence d'un carcinome. Une gastrectomie de Bilroth I a révélé deux foyers cancéreux et une dysplasie de haut degré, ainsi que de multiples foyers de dysplasie de moindre degré. Ce cas donne à penser qu'il peut y avoir un lien entre le traitement au laser et l'installation de maladie gastrique.
W atermelon stomach is a condition characterized by gastrointestinal bleeding, antral red stripes radiating towards the pylorus seen at endoscopy (1), and mucosal ectatic vascular channels, fibrin thrombi and lamina propria fibromuscular hyperplasia on histology $(2,3)$. It is not known to be associated with the development of gastric neoplasia. Laser therapy has become an accepted mode of therapy for watermelon stomach $(4,5)$. In fact, laser and other thermal therapies are in widespread use for a variety of gastrointestinal vascular lesions (6). Although these therapies can be as- sociated with acute perforations, there have been few long term complications reported.

We report a 75-year-old male with chronic renal insufficiency and ischemic heart disease who was treated over five years with neodymium:yttrium aluminum garnet (Nd:YAG) laser approximately every six months. This therapy was associated with the development of deep antral ulcers and ultimately diffuse antral polyps. On biopsy and ultimately at Billroth I gastrectomy, it was proven that the patient had multifocal gastric neoplasia, including two foci of intramu-

Departments of Medicine, Pathology, Radiology and Surgery, University of Manitoba, Winnipeg, Manitoba; and Department of Medicine, Mayo School of Medicine, Rochester, Minnesota

Correspondence and reprints: Dr CN Bernstein, Assistant Professor of Medicine, Section of Gastroenterology, University of Manitoba, GB-445 Health Sciences Centre, 820 Sherbrook Street, Winnipeg, Manitoba R3A 1R9. Telephone 204-787-1434, fax 204-787-4826, e-mail cbernst@cc.umanitoba.ca

Received for publication November 27, 1996. Accepted April 1, 1997 


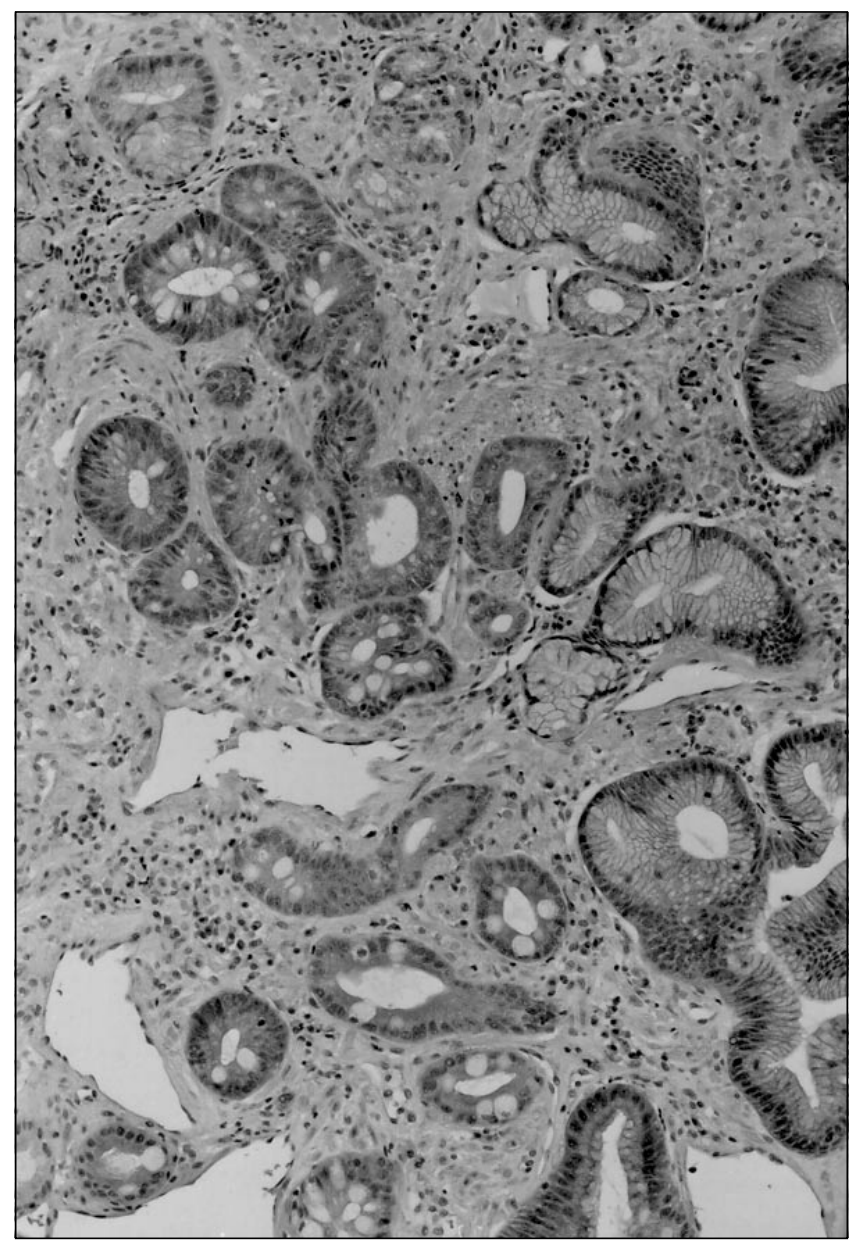

Figure 1) Endoscopically obtained biopsy of the gastric antrum in 1990, revealing chronic active gastritis with intestinal metaplasia and ectatic vessels

cosal carcinoma and multiple foci of low grade dysplasia. Our results suggest a possible link between the diffuse and recurrent application of laser therapy and the development of gastric cancer.

\section{CASE PRESENTATION}

A 71-year-old Caucasian male presented to the Mayo Clinic, Rochester, Minnesota, in January 1990 with chronic occult gastrointestinal blood loss. At that time his hemoglobin was $113 \mathrm{~g} / \mathrm{L}$. He had known hypertension, triple vessel coronary artery disease and chronic renal insufficiency (serum creatinine $267 \mu \mathrm{mol} / \mathrm{L}$ ), and had a pacemaker inserted for sick sinus syndrome one year before. He had no history of portal hypertension or chronic liver disease. On endoscopy he was found to have a watermelon stomach, and antral biopsies revealed organizing microthrombi and focal vascular ectasia, typical of that disorder. Mild chronic gastritis and intestinal metaplasia were also noted (Figure 1). A course of photocoagulative therapy with $\mathrm{Nd}$ :YAG laser was initiated with a power of $60 \mathrm{~W}$ at $1063 \mathrm{~nm}$ in a continuous mode. The patient underwent sequential photocoagulative treatments every six months for the next five years, and he had no further episodes of gastrointestinal bleeding. Treatment ses-

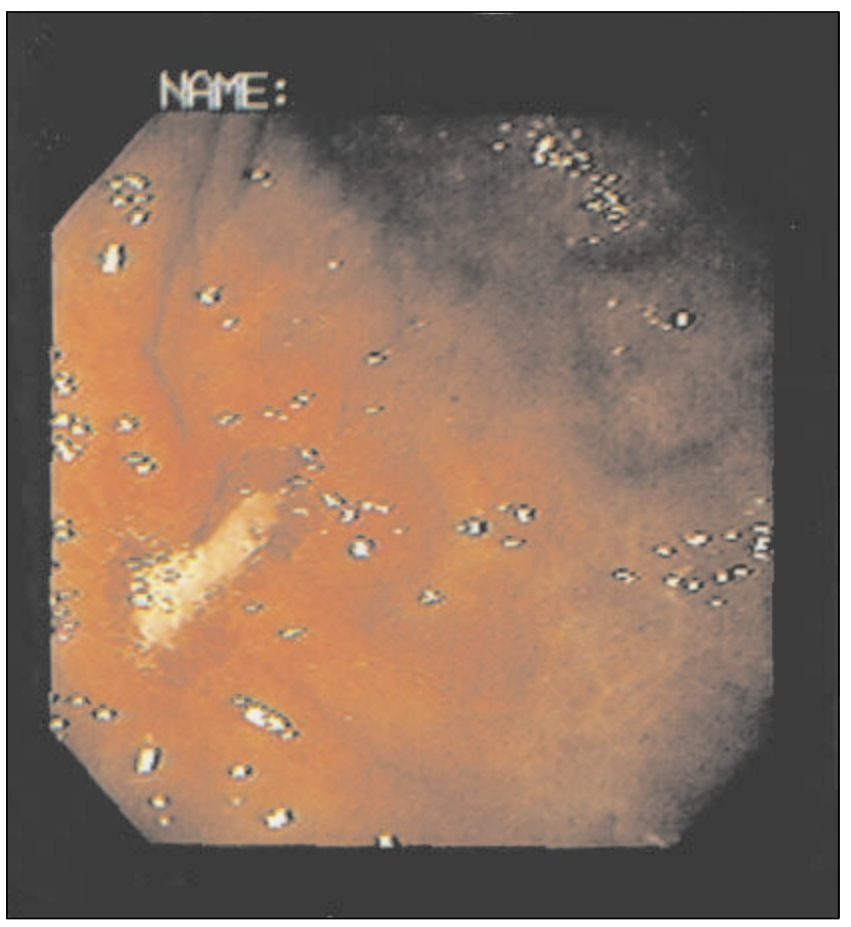

Figure 2) Videoendoscopic photograph in 1994 showing a persistent (but smaller) antral ulcer with adjacent nodular mucosa

sions usually required about $5000 \mathrm{~J}$. By October 1994 the patient's watermelon stomach was thought to be completely healed. However, scattered angiodysplasias were seen in the antrum and body and were treated with a further course of laser therapy. Hemoglobin at that time was $110 \mathrm{~g} / \mathrm{L}$.

The patient presented to the Health Sciences Centre in Winnipeg, Manitoba in November 1994 with hematemesis and syncope. He was not using acetylsalicylic acid or nonsteroidal anti-inflammatory agents. His hemoglobin reached a low of $88 \mathrm{~g} / \mathrm{L}$ and his serum creatinine was stable at $246 \mu \mathrm{mol} / \mathrm{L}$. Upper endoscopy revealed multiple deep and large $(1$ to $3 \mathrm{~cm})$ ulcers in the gastric antrum and 30 angiodysplasia lesions in the antrum, four of which were oozing. The ulcers were thought to be at sites of previous laser therapy. The angiodysplasias were cauterized with monopolar electrocautery. Omeprazole $20 \mathrm{mg} /$ day was initiated to heal the ulcers. Upper endoscopy was repeated in December 1994, revealing partial healing of the antral ulcers, and five nonbleeding angiodysplasias were cauterized. The nonulcerated antrum was nodular (Figure 2). Omeprazole therapy was continued.

In April 1995 the patient's hemoglobin was stable at $105 \mathrm{~g} / \mathrm{L}$. He underwent an elective upper endoscopy that revealed multiple red bumps in the antrum, and all ulcers were healed. No angiodysplasias were identified. A biopsy taken of one antral bump revealed high grade dysplasia/carcinoma-in-situ (Figure 3). An adjacent biopsy from the flat antral mucosa revealed mild chronic gastritis with focal intestinal metaplasia. Helicobacter pylori was not identified by histology, antral biopsy bacterial culture or polymerase chain reaction amplification of a 298 base pair fragment from a 


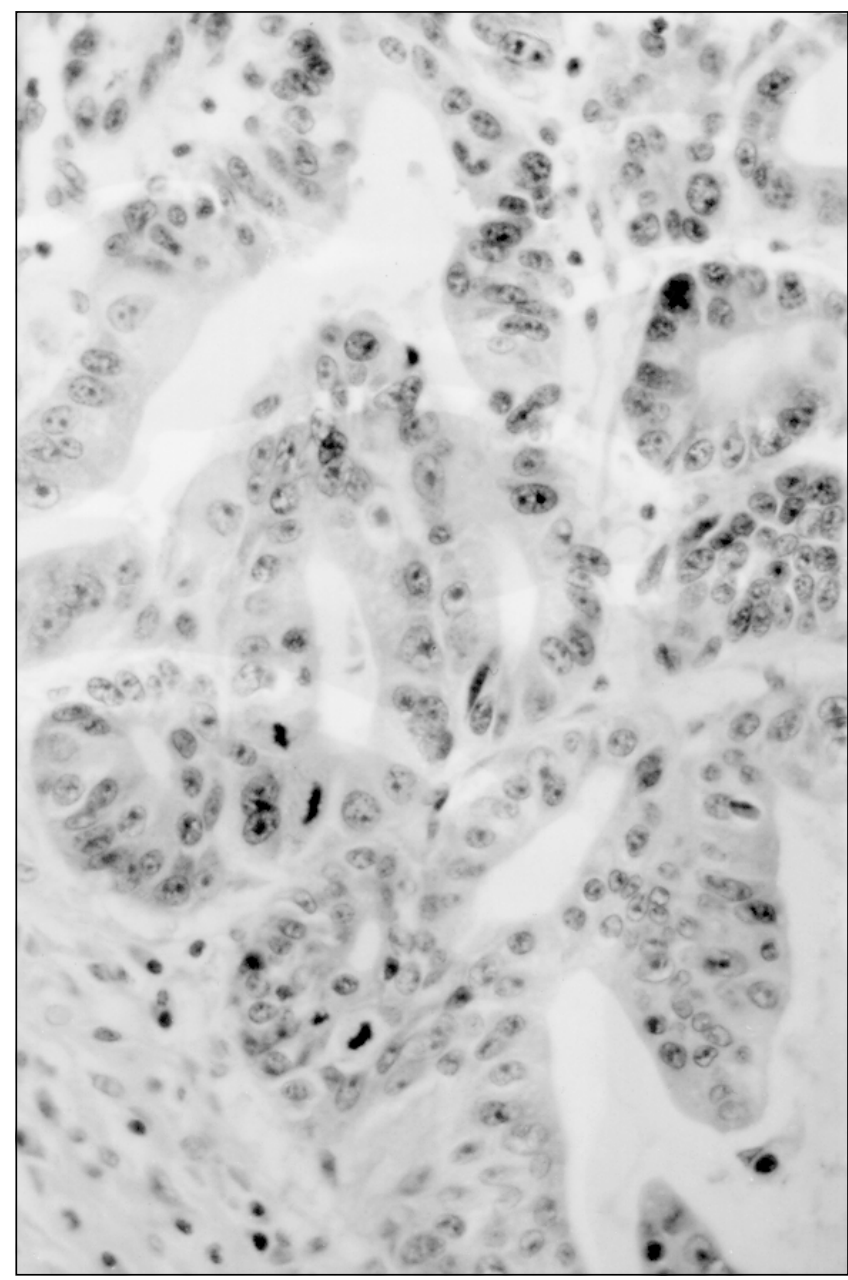

Figure 3) Endoscopic biopsy in 1995 revealing carcinoma-in-situ of the gastric mucosa

species-specific antigen gene sequence performed on antral biopsy tissue. Biopsies from the gastric body also revealed mild chronic gastritis with rare foci of intestinal metaplasia. No H pylori was identified in the gastric body. In May 1995 the patient underwent repeat gastroscopy to facilitate strip biopsies of three bumps. These revealed high grade dyspla-

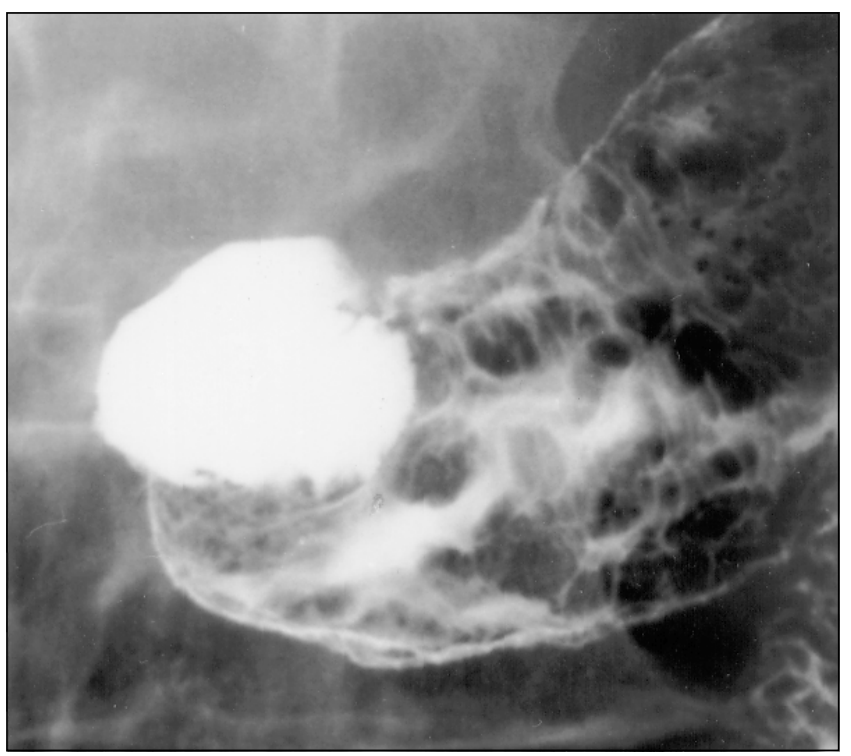

Figure 4) Barium radiograph of the stomach revealing diffuse antral nodularity

sia/carcinoma-in-situ but a clearly demarcated base could not be identified. Complete and incomplete intestinal metaplasia were present in the specimens as well. A double contrast study of the stomach revealed multiple nodular densities in the antrum and distal body varying in size from 0.3 to $1.5 \mathrm{~cm}$ (Figure 4). Whether the lesions extended submucosally could not be determined. The stomach distended well on $\mathrm{x}$-ray.

In August 1995 the patient underwent a Billroth I gastrectomy. The bumpy mucosa was confined to the antrum and distal body (Figure 5), and frozen sections intraoperatively of the proximal resection margin revealed no evidence of dysplasia. The antral histology revealed two foci of intramucosal carcinoma with no invasion beyond the muscularis mucosae and multiple foci of low grade dysplasia. There was no evidence of watermelon stomach. Postoperatively he had a brief episode of congestive heart failure that was easily managed with flurosemide. His renal function did not dete-
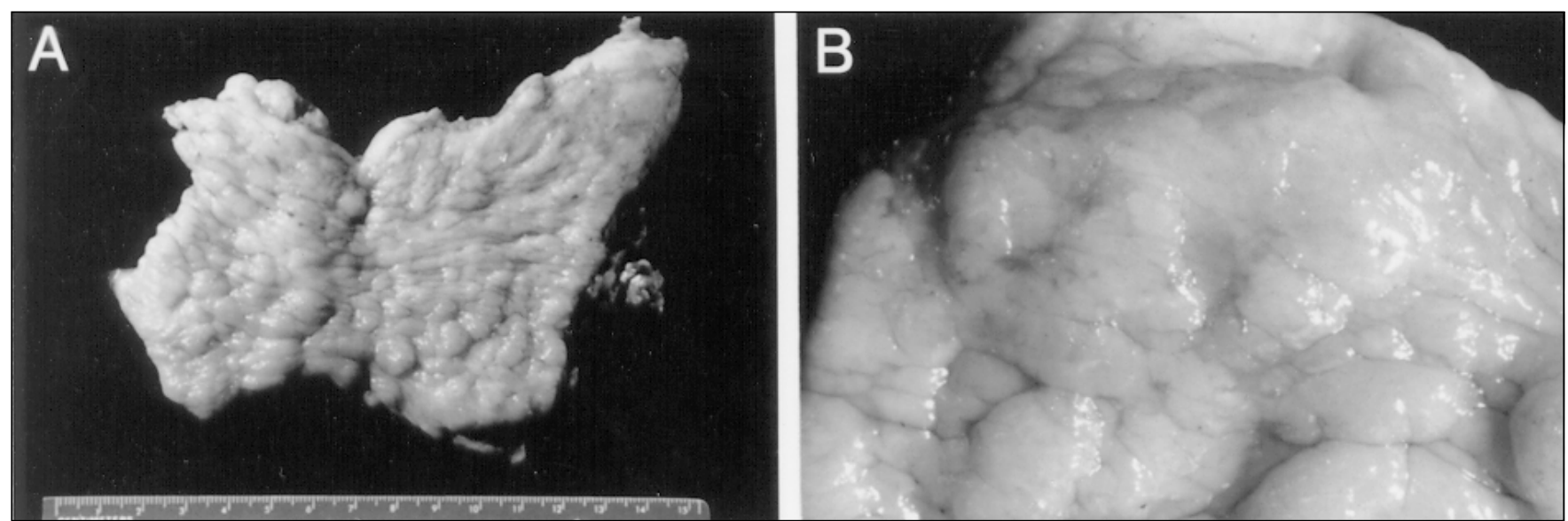

Figure 5) A Resection specimen revealing nodular antrum; B Close-up photograph of resected antrum 
riorate. In November 1995 he was managing well, eating more frequent and smaller meals, and was otherwise asymptomatic. His hemoglobin was stable at $110 \mathrm{~g} / \mathrm{L}$.

\section{DISCUSSION}

Watermelon stomach - or gastric antral vascular ectasia (GAVE) syndrome - is not typically associated histologically with chronic atrophic gastritis (type B) or intestinal metaplasia $(2,3)$, conditions known to be linked to the development of gastric neoplasia $(7,8)$. Furthermore, laser or any thermal type of therapy (including heater probe or monopolar or bipolar electrocautery), which is now in widespread use to treat gastrointestinal vascular lesions (6), has not been reported to be associated with the ultimate development of dysplastic change in the epithelium. Recently Geller et al (9) noted that 60 patients undergoing Nd:YAG laser therapy for watermelon stomach and followed for a median of 20 months developed no neoplastic changes on sequential endoscopies. However, it is not clear whether these patients underwent random antral biopsies. Four of their patients developed antral polyps, all of which were histologically hyperplastic with prominent foveolar hyperplasia. Their data supported the notion that laser therapy for watermelon stomach is safe and without long term consequences.

Laser photocoagulation produces a significant thermal injury as evidenced by the frequent occurrence of antral cicatricial scarring (10). Laser therapy is always followed by ulceration. These lesions heal by fibrosis and are covered with an atrophic epithelium (11). It has been assumed that healing from this type of injury is with regenerative but not neoplastic epithelium. Other deep burn injuries, for instance in the skin, reportedly were associated with the development of carcinoma when allowed to heal simply by secondary intention (12). Peacock et al (12) suggest that any wound in which re-epithelization is retarded long enough is in danger of malignant transformation. The length of time for carci-

\section{REFERENCES}

1. Jabbari M, Cherry R, Lough JO, Daly DS, Innear DG, Goresky CA. Gastric antral vascular ectasia: the watermelon stomach. Gastroenterology 1984;87:1165-70.

2. Suit PF, Petras RE, Bauer TW, Petrini JL Jr. Gastric antral vascular ectasia: a histologic and morphometric study of the "watermelon stomach". Am J Surg Pathol 1987;11:750-7.

3. Gilliam JH, Geisinger KR, Wu WC, Weidner N, Richter JE. Endoscopic biopsy is diagnostic in gastric antral vascular ectasia. The watermelon stomach. Dig Dis Sci 1989;34:885-8.

4. Gostout CJ, Ahlquist DA, Radford CM, Vigglano TR, Bowyer BA, Balm RK. Endoscopic laser therapy for watermelon stomach. Gastroenterology 1989;96:1462-5

5. Liberski SM, McGartity TJ, Hartle RS, Varano V, Reynolds D. The watermelon stomach: long term outcome in patients treated with ND:YAG laser therapy. Gastrointest Endosc 1994;40:584-7.

6. Cook DJ, Guyatt GH, Salena BJ, Laine L. Endoscopic therapy for acute nonvariceal upper gastrointestinal hemorrhage; a meta-analysis. Gastroenterology 1992;102:139-48.

7. Walker IR, Strickland RG, Ungar B, Mackay IR. Simple atrophic gastritis and cancer. Gut 1971;12:906-11.

8. Filipe MI, Potet F, Bogomoletz WV, et al. Incomplete sulphomucin-secreting intestinal metaplasia for gastric cancer. noma to occur is proportional to the wavelength of the radiant energy (many years before carcinoma develops in a burn scar from wavelengths so long as to be nearly in the visible spectrum, compared with 12 to 24 months in injuries caused by $\mathrm{x}$-ray or gamma radiation).

It is possible that our patient's chronic active gastritis with intestinal metaplasia predisposed him to development of multifocal gastric neoplasia independent of his watermelon stomach or its treatment. Nonetheless, we tracked the response to laser therapy (five years into its course), witnessing the development of multifocal deep ulceration and subsequently multiple antral polyps. The multifocal nature of the neoplastic changes, including frank cancer and lower grades of dysplasia, argues favourably for a broad field injury that might have been induced by the laser.

We cannot unequivocally prove that laser therapy was the cause of this patient's gastric neoplasia. However, this case highlights the potential for serious late sequelae of recurrent laser therapy. This finding may affect cases where laser is used as curative therapy for early gastric cancer (13) or gastrointestinal cancer elsewhere $(14,15)$. Perhaps we should be particularly cautious of the potential neoplastic effects of repeated thermal treatments in patients who have underlying intestinal metaplasia of the stomach. Prospective studies of random biopsies to search for dysplastic changes in patients treated with diffuse and repeated laser or other thermal therapies applied to the stomach should be considered. Such studies are likely best suited to centres that have initiated long term studies of laser therapy for gastric lesions. We are not, however, advocating that clinicians begin a surveillance process of these types of patients until there is more evidence that this is a problem that warrants a follow-up surveillance approach. Furthermore, we encourage the reporting of neoplastic change in sites of previous thermal injury to help define the true long term consequences of what has now become standard therapy.

Preliminary data from a prospective study from three centres. Gut 1985;26:1319-26

9. Geller A, Gostout CJ, Balm RK. Development of hyperplastic polyps following laser therapy for watermelon stomach. Gastrointest Endosc 1996;43:54-6.

10. Gostout CJ, Viggiano TR, Ahlquist DA, Wang KK, Larson MV, Balm $\mathrm{R}$. The clinical and endoscopic spectrum of the watermelon stomach. J Clin Gastroenterol 1992;15:256-63.

11. Rutgeerts P, Van Gompel F, Geboes K, Vantrappen G, Broeckaert L, Coremans G. Long term results of treatment of vascular malformations of the gastrointestinal tract by Neodymium Yag laser photocoagulation. Gut 1985;26:586-93.

12. Peacock EE Jr, Kelman Cohen I. Wound healing. In: McArthy JG, ed. Plastic Surgery. Volume 1: General Principles. Philadelphia: WB Saunders Co, 1990:161-84.

13. Yasuda K, Mizuma Y, Nakajima M, Kawai K. Endoscopic laser treatment for early gastric cancer. Endoscopy 1993;25:451-4.

14. Brunetaud JM, Maunoury V, Cochelard D, Boniface B, Cortot A, Paris JC. Endoscopic laser treatment for rectosigmoid villous adenoma: factors affecting the results. Gastroenterology 1989;97:272-7.

15. Lambert R, Ponchon T, Chavaillon A, Berger F. Laser treatment of tumors of the papilla of Vater. Endoscopy 1988;20(Suppl 1):227-31. 


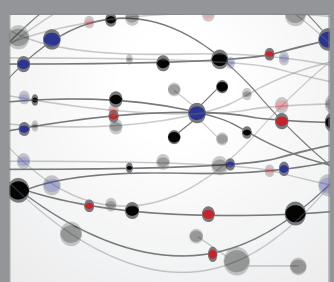

The Scientific World Journal
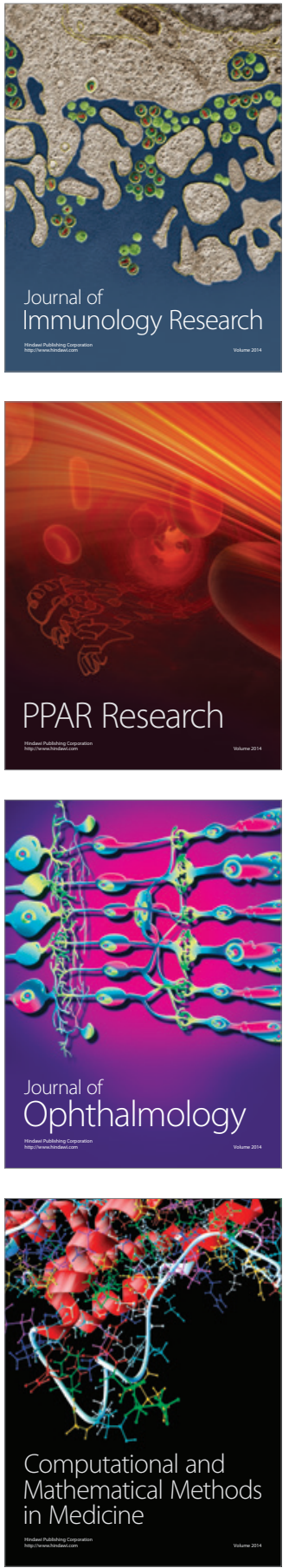

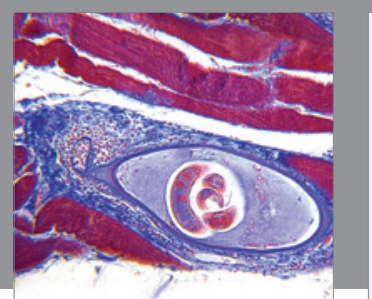

Gastroenterology Research and Practice

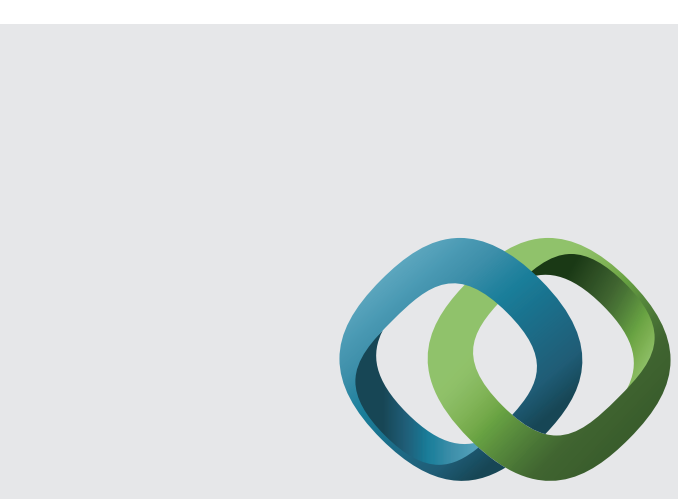

\section{Hindawi}

Submit your manuscripts at

http://www.hindawi.com
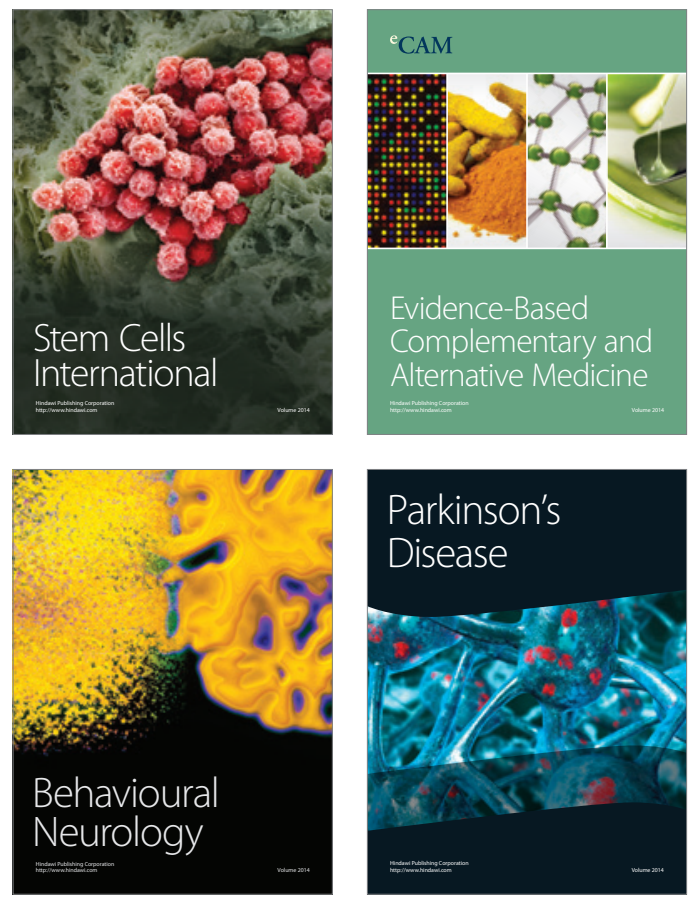
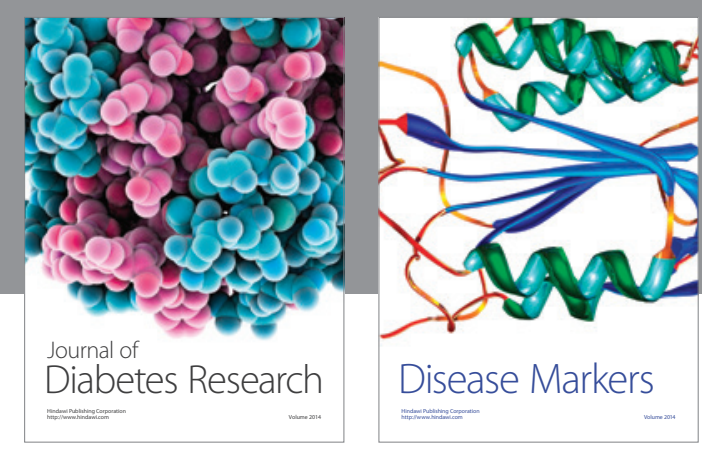

Disease Markers
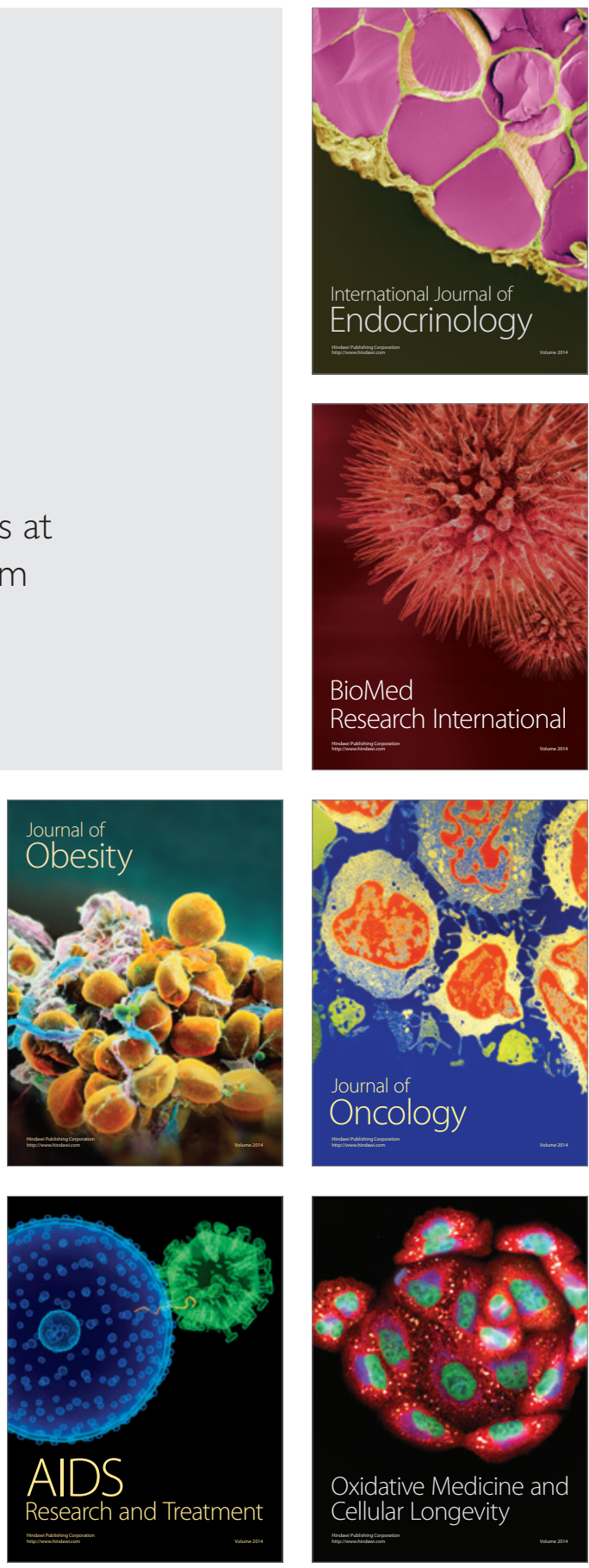